\title{
Towards a Photochemical Synthesis of Peptides
}

\author{
Christian G. Bochet*
}

\begin{abstract}
The laboratory preparation of peptides, once a challenge, is now a standard operation that can be automatised. However, the need for particular protecting groups requiring relatively harsh conditions for their removal (strong acids or bases) and reactive coupling agents can be problematic in specific cases (e.g. in a cell or in a microfluidic device). In this account, we describe our efforts towards a fully photochemical approach to peptide synthesis, where both the coupling and the deprotection steps use light instead of reagents. In order to selectively promote one of the two steps at a time, monochromatic light is used.
\end{abstract}

Keywords: Amidation · Amides · Peptide synthesis · Photochemistry · Protecting groups

Peptides and proteins occupy a central part in the chemistry of life, and it is not a surprise that their synthetic preparation became a challenge for chemists very early on. ${ }^{[1]}$ The intuitively rightful disconnective analysis of these macromolecules most frequently identifies the amide bond as the key element, and literally hundreds of methods have been devised to exploit the intrinsic nucleophilicity of an amine and the electrophilicity of an activated carboxyl group to create this bond. The latter has been augmented by various synthetic tricks, e.g. by converting the canonic $\mathrm{OH}$ group into a better leaving group. Thus, acid chlorides or fluorides, various carbodiimide-based activated esters, triazole derivatives, hydroxysuccinimide derivatives, uronium derivative, and others, have been introduced, solving completely or partially the problems associated with cost, reaction rates, racemization, azlactone formation, ease of purification etc. ${ }^{[2]}$ The most significant advance was introduced in the 1960s, with the attachment of the growing peptidic fragment to an insoluble polymeric support, which paved the way to automated procedures, nowadays routinely used without significant human intervention. ${ }^{[3,4]}$ This quantum leap in the synthesis of peptides was recognized by the award of the Nobel Prize in chemistry to Bruce Merrifield in 1984. Less visible, but equally important for the success of these methods, was the development of protecting groups capable of surviving the synthesis of the peptide, i.e. being orthogonal with respect to the other functional groups (this term was coined by Merrifield himself). ${ }^{5]}$ Emerging from this evolution, the acidlabile Boc group ${ }^{[6]}$ and the base-labile Fmoc group ${ }^{[7]}$ have become now gold standards in the field.

The above enthusiastic introduction might give the reader the impression that peptide synthesis is a solved problem, leaving space only to incremental improvement of a very robust technology. This is obviously not the case, and this thematic issue clearly shows that creative research is still able to open new horizons and to give to the chemist, biologist or material scientist tools to address problems that appeared unsolvable just a few years ago.

Based on our research on wavelength-selective photochemical reactions, more particularly in our search for chromatically orthogonal photosensitive protecting groups (i.e. groups that could be selectively removed photochemically using a specific wavelength, without signif- icant cross-reactivity), [8-11] we wondered whether we could perform both fundamental steps in peptide synthesis at two different wavelengths. If that would be the case, then a reagentless peptide synthesis might become possible, since the only activator for the reaction would be just light. Thus, we embarked on a program aiming at finding a carboxyl group activator that would operate at a different wavelength than the removal of the protecting group.

\section{Photochemical Activation of a Carboxyl Group}

We initially worked on the design of an ideal group that would be totally inert towards nucleophilic attack, but would be converted in situ into a reactive acyl transfer reagent upon photolysis. ${ }^{[12]}$ Early candidates were amidopyridine derivatives such as 1 (Scheme 1). ${ }^{[13]}$ Paralleling the structurally related photo-Fries rearrangement (which is well known on phenol esters), we banked on a photoinduced migration of the acyl group to the pyridine-type nitrogen atom, leading to an intermediate reminiscent of the DMAP-accelerated acylation of alcohols. 
However, photolysis of $\mathbf{1}$ gave a complex mixture of products, including, among many others, traces of the product where the acyl group indeed followed a photo-Fries rearrangement, but in the wrong direction! We corrected this problem, not too elegantly, by just flanking both ortho positions with nitrogen atoms, bringing the amidopyrimidines $\mathbf{2 a}$,b (literally) into the spotlight. Despite the disappointment from a synthetic perspective, it was still a bittersweet intellectual satisfaction to get a $47 \%$ yield of acyl transfer in the irradiation of $\mathbf{2 b}$ in the presence of an amine. However, the mechanistic considerations were just the reason for attempting the reaction; its partial success by no means validated the initial hypothesis.

Less creative, but massively more efficient, a careful literature search showed that Patchornik et al. had developed a group that seemed to fulfill our requirements: the acylated 5-bromo-7-nitroindoline (abbreviated Bni, Scheme 2).[14,15] Used on numerous occasions as a protecting group ${ }^{[16]}$ or in caging compounds, ${ }^{[17]}$ these nitroindoline derivatives were much more rarely used as acyl transfer groups, despite the original impressive example of racemization-free synthesis of a peptide.[15] Unknowingly parallel work by Nicolaou and Winssinger and us exploiting this reaction for the preparation of amides

was published in 2001.[18,19] We used the more reactive dinitroindoline derivatives $\mathbf{4 b}$, and studied their reaction mechanism together with John Toscano in Baltimore by time-resolved FTIR, confirming an earlier hypothesis of a photoinduced $N-O$ acyl transfer, generating a very reactive acyl-nitro intermediate, immediately trapped by a nucleophile, in general an amine. ${ }^{[20]} \mathrm{We}$ later expanded the scope of the reaction to the formation of esters. ${ }^{[21]}$

\section{Preparing Amino Acid-containing Building Blocks}

Despite the success in triggering the formation of amide bonds by light, we still faced the challenge of preparing more complex acyl donors than simple alkyl chains. Attempts at direct acylation of the very poorly nucleophilic dinitroindolines $\mathbf{5 a}$ or $\mathbf{5 b}$ systematically failed in our hands. We thus went for a slightly less direct, but still high yielding route: the introduction of the amino acid derivative in an acyclic precursor 6 where the nitrogen atom is not deactivated by the dinitroaromatic ring, and then cyclize it into an indoline by an intramolecular Pd-catalyzed arene amidation (Scheme 3). ${ }^{[22]}$ With this strategy, we prepared a dozen different photoactivable amino acid derivatives.

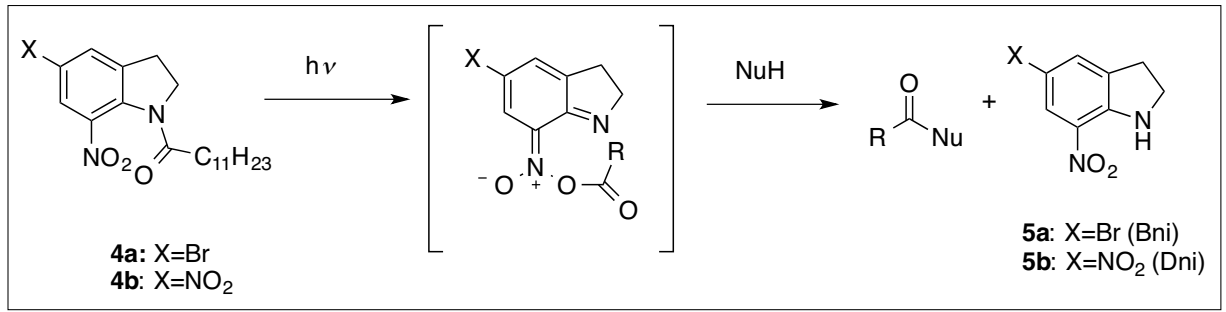

Scheme 2. Nitroindoline derivatives as efficient photoacylating agents.

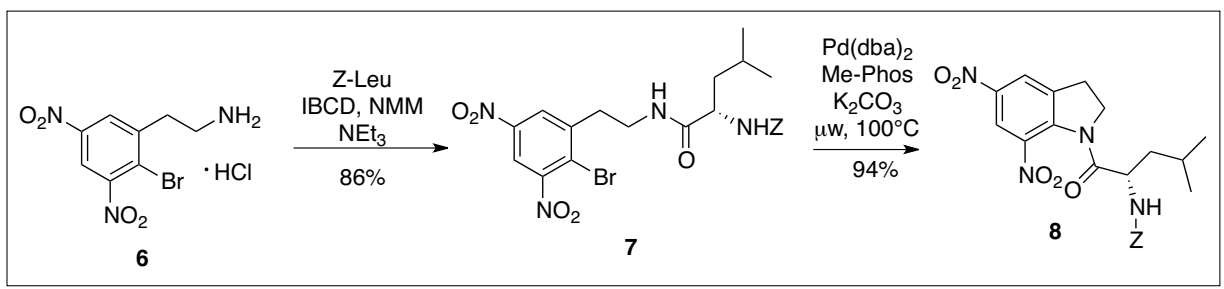

Scheme 3. Preparation of photoactivable amino acid derivatives. IBCD $={ }^{i} \mathrm{BuOCOCI} ; \mathrm{NMM}=$ $\mathrm{N}$-methyl-morpholine.

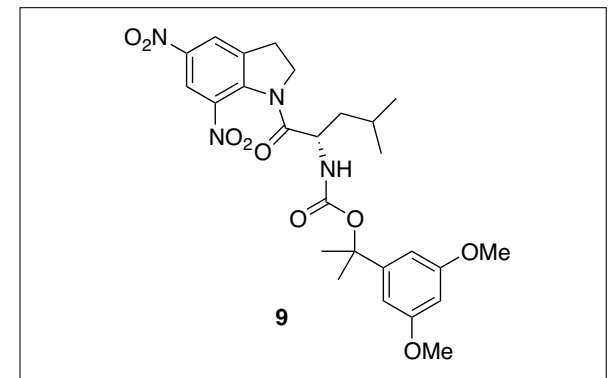

Fig. 1. Ddz-amino acid derivative.

\section{Photolabile Protecting Groups that are Chromatically Orthogonal to the Photoamidation Reaction}

As the typical operating wavelength for the indoline-based acylation lies between 350 and $420 \mathrm{~nm}$, a chromatically orthogonal protecting group should react either at a longer or shorter wavelength. The former range would pose two problems: a) no such groups were available at that time, and b) since the deprotection systematically occurs after the coupling step, the photolabile group should be strictly unreactive at the coupling wavelength, a feature that can be delicate to attain. On the other hand, a shorter wavelength ensures that nothing happens during the coupling step, and, strictly speaking, chromatic orthogonality is not necessary: a simple modulated lability is enough. ${ }^{[23]}$ We chose the $\alpha, \alpha$-dimethyl-3,5-dimethoxybenzyloxycarbonyl (Ddz) group (Fig. 1), which has a high photoreactivity at $300 \mathrm{~nm}$ and shorter.[24]

\section{Formation of Peptides}

We then tested the overall feasibility of the scheme, by attempting to prepare a simple dipeptide: H-Phe-Ala-OH. ${ }^{[25]}$ The coupling step proceeded smoothly at 385 $\mathrm{nm}$, as well as the deprotection at $300 \mathrm{~nm}$. In order to check for a potential epimerization, an unwanted side reaction sometimes observed in peptide coupling, we prepared the diastereomeric pair of dipeptides 12a and 12b, starting with L-Ala-Dni 10 and its enantiomer D-Ala-Dni ent-10, and no cross-contamination was observed (Scheme 4).

With this result in hand, we embarked on the synthesis of a full pentapeptide (Scheme 5), the OGP $(10,14),{ }^{[26]}$ which is the active portion of an osteogenic growth protein (we chose it based on the library of photoactivable amino acids that we had in hand, and not for its biological properties). Thus, exposure to $385 \mathrm{~nm}$ light of a mixture of glycine (the starting amino acid of the peptide) and photoactivable glycine (the next building block) smoothly led to the protected dipeptide, which was then deprotected by exposure to $300 \mathrm{~nm}$ light.

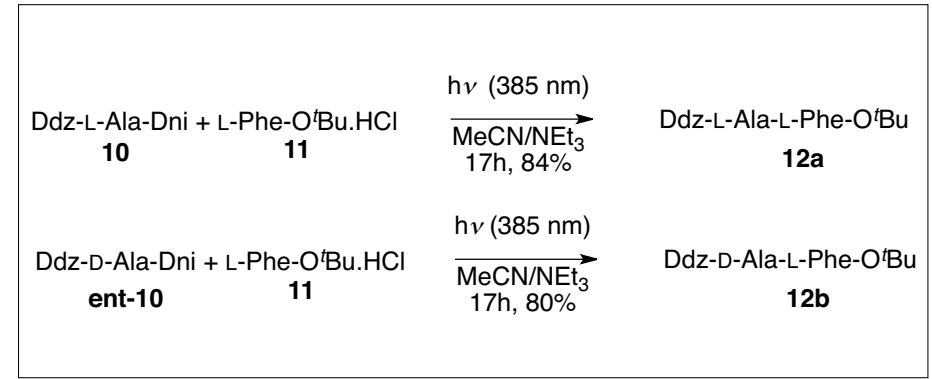

Scheme 4. Epimerization-free formation of dipeptides. 
Iterations of the same sequence of steps allowed us to isolate the protected pentapeptide, without the use of reagents other than each building block (Scheme 6).

\section{Conclusion}

This work constitutes a proof of principle for a full photochemical synthesis of peptides. Of course, several limitations remain, among them the tedious and costly preparation of the building blocks, making the overall strategy at this stage far less attractive than the classical Merrifield-type synthesis. To replace that synthesis was actually never our intention. On the other hand, wherever classical methods cannot be applied (microfluidic devices, living cells,...), variations of this approach could be considered and specific applications optimized. Photochemical reactions have been carried out in living organisms, such as zebrafish.[27]

\section{Acknowledgement}

The author is deeply indebted to all the coworkers who contributed directly or indirectly to this project, and whose names are mentioned in the original publications, in particular Céline Helgen, Aurélien Blanc, Jean-Luc Débieux and Anne Cosandey.

Received: September 28, 2013

[1] E. Fischer, Berichte der deutschen chemischen Gesellschaft 1903, 36, 2094.

[2] A. El-Faham, F. Albericio, Chem. Rev. 2011, 111, 6557.

[3] R. B. Merrifield, Science 1986, 232, 341.

[4] R. B. Merrifield, Science 1965, 150, 178.

[5] R. B. Merrifield, G. Barany, W. L. Cosand, M. Engelhard, S. Mojsov, Pept., Proc. Am. Pept. Symp. 5th 1977, 488.

[6] G. W. Anderson, A. C. McGregor, J. Am. Chem. Soc. 1957, 79, 6180 .

[7] L. A. Carpino, G. Y. Han, J. Org. Chem. 1972, 37, 3404.

[8] C. G. Bochet, Synlett 2004, 2268.

[9] A. Blanc, C. G. Bochet, J. Org. Chem. 2002, 67, 5567.

[10] C. G. Bochet, Tetrahedron Lett. 2000, 41, 6341.

[11] C. G. Bochet, Angew. Chem. Int. Ed. 2001, 40, 2071.

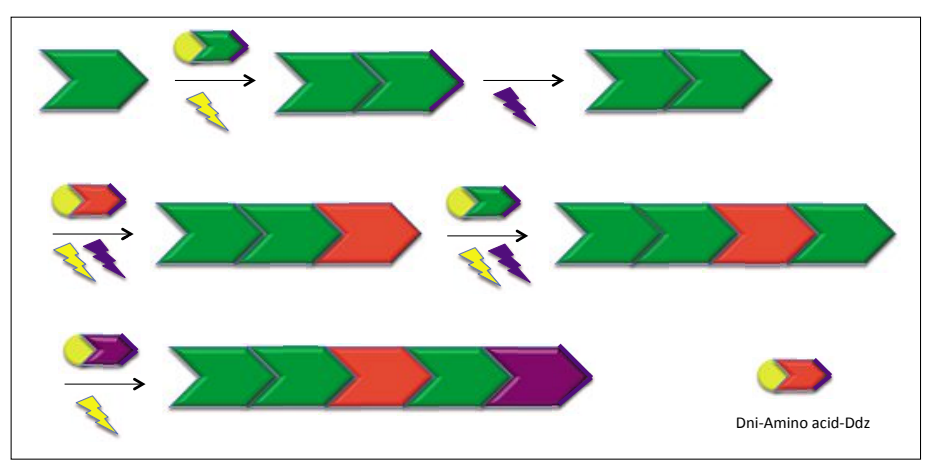

Scheme 5. General strategy for the synthesis of a pentapeptide.

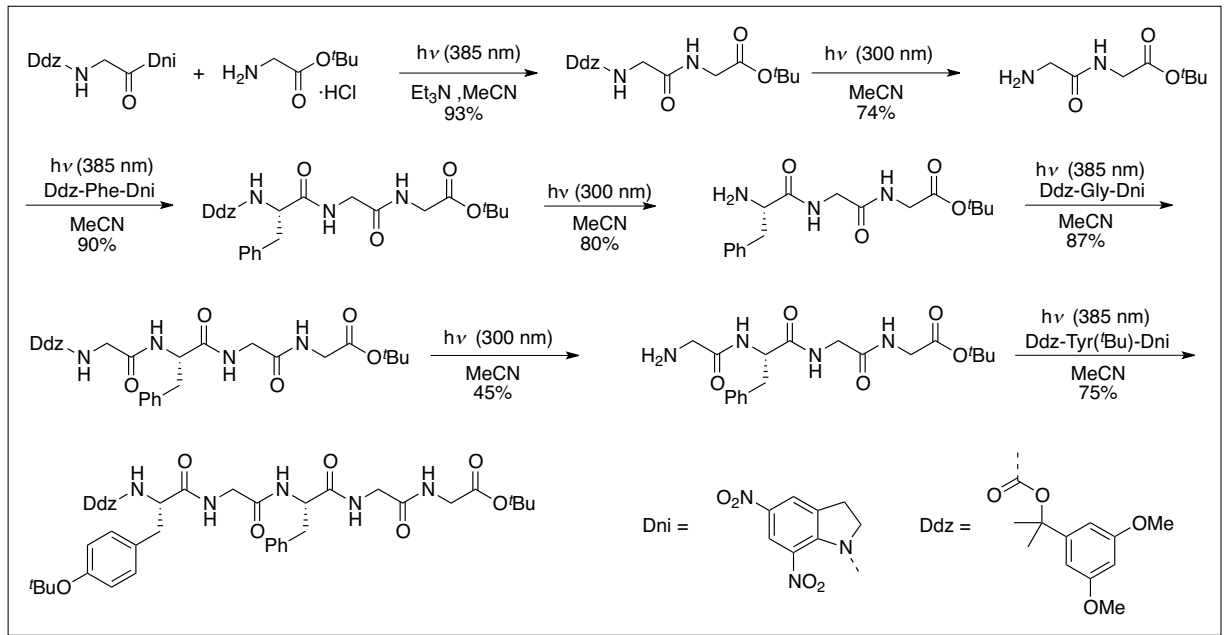

Scheme 6. Full photochemical synthesis of OGP(10,14).

[12] J.-L. Débieux, C. G. Bochet, J. Phys. Org. Chem. 2010, 23, 272.

[13] C. Helgen, C. G. Bochet, Heterocycles 2006 , 67, 797.

[14] B. Amit, D. A. Ben-Efraim, A. Patchornik, J. Am. Chem. Soc. 1976, 98, 843.

[15] S. Pass, B. Amit, A. Patchornik, J. Am. Chem. Soc. 1981, 103, 7674

[16] G. Goissis, B. W. Erickson, R. B. Merrifield, Pept., Proc. Am. Pept. Symp., 5th 1977, 559.

[17] J. Morrison, P. Wan, J. E. T. Corrie, G. Papageorgiou, Photochem. Photobiol. Sci. 2002, 1, 960.

[18] K. C. Nicolaou, B. S. Safina, N. Winssinger, Synlett 2001, 900.

[19] C. Helgen, C. G. Bochet, Synlett 2001, 1968.

[20] A. D. Cohen, C. Helgen, C. G. Bochet, J. P. Toscano, Org. Lett. 2005, 7, 2845.

[21] J.-L. Débieux, A. Cosandey, C. Helgen, C. G. Bochet, Eur. J. Org. Chem. 2007, 2073.
[22] J.-L. Débieux, C. G. Bochet, J. Org. Chem. 2009, 74, 4519.

[23] M. Schelhaas, H. Waldmann, Angew. Chem. Int Ed. 1996, 35, 2056

[24] C. Birr, W. Lochinger, G. Stahnke, P. Lang, Justus Liebigs Ann. Chem. 1972, 763, 162.

[25] J.-L. Débieux, C. G. Bochet, Chem. Sci. 2012, 3, 405 .

[26] A. Spreafico, B. Frediani, C. Capperucci, A. Leonini, D. Gambera, P. Ferrata, S. Rosini, A. Di Stefano, M. Galeazzi, R. Marcolongo, $J$. Cell. Biochem. 2006, 98, 1007.

[27] D. K. Sinha, P. Neveu, N. Gagey, I. Aujard, C. Benbrahim-Bouzidi, T. Le Saux, C. Rampon, C. Gauron, B. Goetz, S. Dubruille, M. Baaden, M. Volovitch, D. Bensimon, S. Vriz, L. Jullien, ChemBioChem 2010, 11, 653. 